EXTENDED REPORT

\title{
Efficacy of anakinra in active ankylosing spondylitis: a clinical and magnetic resonance imaging study
}

\author{
A L Tan, H Marzo-Ortega, P O'Connor, A Fraser, P Emery, D McGonagle
}

Ann Rheum Dis 2004;63:1041-1045. doi: 10.1136/ard.2004.020800

See end of article for authors' affiliations

Correspondence to: Professor D McGonagle, Academic Unit of Musculoskeletal Disease, Leeds General Infirmary, Great George Street, Leeds LSI 3EX, UK; d.g.mcgonagle@ leeds.ac.uk

Accepted 16 March 2004 Published online first 5 April 2004
Objective: To determine the efficacy of anakinra, an interleukin 1 receptor antagonist in active ankylosing spondylitis (AS), and to investigate the effect of anakinra treatment on spinal enthesitis/osteitis using magnetic resonance imaging (MRI).

Methods: A 3 month open label study of anakinra (100 mg subcutaneous injection daily) was carried out in nine patients with active AS who had back pain and an increased acute phase response, and who had failed to respond to at least one non-steroidal anti-inflammatory drug. Clinical assessment included the Bath AS Functional Index (BASFI), Bath AS Disease Activity Index (BASDAI), and AS Quality of Life (ASQoL) before and after treatment. Fat suppressed MRI of the spine and sacroiliac joints was performed with a $1.5 \mathrm{~T}$ scanner at baseline and at 3 months to determine the effect of treatment on spinal enthesitis/ osteitis.

Results: Significant improvement was found in the BASFI (median baseline 5.88, 3 months 3.63, $p=0.021$ ), BASDAI (median baseline 5.63, 3 months 3.48, $p=0.028$ ), ASQoL (median baseline 12, 3 months $8, p=0.011$ ) and laboratory measures reflecting inflammation, with $C$ reactive protein (median baseline $31 \mathrm{mg} / \mathrm{l}, 3$ months $17 \mathrm{mg} / \mathrm{l}, \mathrm{p}=0.036$ ) and erythrocyte sedimentation rate (median baseline $19 \mathrm{~mm} / 1 \mathrm{st} \mathrm{h}, 3$ months $15 \mathrm{~mm} / 1 \mathrm{st} h, p=0.008$ ) also showing significant improvement. Six patients $(67 \%)$ achieved the Assessments in AS (ASAS) Working Group criteria of $20 \%$ improvement. Of the 38 regions of enthesitis/osteitis determined by MRI at baseline, 23 (61\%) either improved or regressed completely.

Conclusions: This open label pilot study suggests that anakinra is effective in controlling the clinical manifestations of AS. The clinical response was reflected by an improvement in MRI determined spinal enthesitis/osteitis.
$\mathrm{T}$ he spondyloarthropathies (SpAs) are a heterogeneous group of diseases including ankylosing spondylitis (AS), psoriatic arthritis, reactive arthritis, enteropathic arthritis, and undifferentiated SpA. Collectively these arthritides are characterised by enthesitis/osteitis, which includes axial disease manifestations in addition to synovitis that account for some of the peripheral disease manifestations. ${ }^{1}$ Until recently the treatment options for AS and SpA were limited, with drugs including sulfasalazine and methotrexate showing little efficacy in comparison with that seen in rheumatoid arthritis (RA).

In both RA and SpA the introduction of tumour necrosis factor $\alpha(\mathrm{TNF} \alpha)$ blocking agents has heralded an exciting new era in the treatment of these diseases, with TNF $\alpha$ blockade having good efficacy in both RA and SpA..$^{2-6}$ Infliximab has been approved in the European Union for AS, and etanercept has been granted the Food and Drug Administration approval in America for the treatment of psoriatic arthritis. Like TNF $\alpha$ the proinflammatory cytokine, interleukin l (ILl), is also pivotal in the inflammatory cascade. ${ }^{7}$ Up regulation of ILl has been reported in AS in the peripheral tissues, and ILl polymorphisms are associated with AS..$^{8-11}$ ILl blockade in experimental arthritis has been shown to ameliorate joint damage. ${ }^{12}$ A prominent feature of AS and SpA is diffuse osteitis in the spine and peripheral sites, ${ }^{13}$ and this is likely to be associated with osteoclastic activation that contributes to joint damage at these sites. ILl has a prominent role in osteoclastic mediated bone damage. ${ }^{14}$ Therefore ILl antagonism may be of central importance in controlling the osteitis associated with AS and SpA.

Magnetic resonance imaging (MRI) represents an exciting development in the diagnosis and monitoring of treatment in
AS and SpA and can monitor axial enthesitis/osteitis that cannot be assessed clinically or by radiography. MRI has been used to show that the majority of pathological changes in the spine and bone either regress completely or improve after biological blockade with etanercept or infliximab. ${ }^{2}{ }^{15}$

Because ILl has a crucial role in the inflammatory cascade and has been shown to be up regulated in AS, this study aimed at assessing the effect of anakinra, an ILl receptor antagonist, in the treatment of AS in a proof of concept clinical and imaging study. MRI was used specifically to assess the response of enthesitis and osteitis in the axial skeleton to anakinra.

\section{PATIENTS AND METHODS}

\section{Patients and study protocol}

The study is a single centre, 3 month, open label pilot proof of concept trial approved by the local ethics committee. Nine patients with AS according to the New York modified criteria ${ }^{16}$ were recruited for the study, with all patients giving written informed consent beforehand. All patients had active disease as defined by a visual analogue scale (VAS)

Abbreviations: ANA, antinuclear antibody; $A S$, ankylosing spondylitis; ASAS, Assessments in AS; ASQoL, AS Quality of Life; BASDAl, Bath AS Disease Activity Index; BASFI, Bath AS Functional Index; CRP, C reactive protein; ESR, erythrocyte sedimentation rate; FOV, field of view; IL, interleukin; MASES, Maastricht AS Enthesitis Score; MRI, magnetic resonance imaging; NBP, night back pain; NSA, number of signals averaged; NSAID, non-steroidal anti-inflammatory drug; PGA, patient global assessment; RA, rheumatoid arthritis; SIJ, sacroiliac joint; SpA, spondyloarthropathy; STIR, short $\tau$ inversion recovery; TBP, total back pain; TE, time to echo; TNF $\alpha$, tumour necrosis factor $\alpha$; TR, repetition time; TSE, turbo spin echo VAS, visual analogue scale 
Table 1 Summary of patient demographics and clinical and functional assessments at baseline, week 12 after treatment, and weeks 14-19 (2-7 weeks after stopping treatment) ${ }^{*}$

\begin{tabular}{llll}
\hline & Baseline & Week 12 & Weeks 14-19 \\
\hline Age (years), mean (range) & $45(31-58)$ & & \\
Men (\%) & 100 & & \\
Disease duration (years), mean (range) & $18(3-33)$ & & \\
HLA-B27 positive (\%) & 87.5 & & \\
CRP (mg/l) & $31(14-65)$ & $17(6-47) \dagger$ & $240(140-450)$ \\
ESR (mm/1 st h) & $19(13-66)$ & $15(5-58) \dagger$ & $22(8-98) \dagger$ \\
EMS (min) & $60(15-120)$ & $20(5-120)$ & $60(20-180) \dagger$ \\
VAS scores (0-100 mm scale) & $68(40-91)$ & $35(8-94) \dagger$ & $59(24-94)$ \\
Night back pain & $65(44-91)$ & $41(5-85)$ & $63(40-95) \dagger$ \\
Total back pain & $67(42-91)$ & $41(3-80)$ & $74(28-96) \dagger$ \\
Patient's global assessment & $5.88(2.81-7.49)$ & $3.63(0.63-8.24) \dagger$ & $6.13(3.52-8.74) \dagger$ \\
BASFI score (0-10) & $5.63(3.83-7.8)$ & $3.48(0.48-7.68) \dagger$ & $6.55(2.82-8.27) \dagger$ \\
BASDAl score (0-10) & $12(5-16)$ & $8(0-15) \dagger$ & $12(5-17) \dagger$ \\
ASQoL score (0-18) & & & \\
\hline
\end{tabular}

*Except where indicated otherwise, values are the median (range); $\uparrow$ significant values $(p<0.05)$ by Wilcoxon's matched pairs signed rank test.

CRP, C reactive protein; ESR, erythrocyte sedimentation rate; EMS, early morning stiffness; VAS, visual analogue scale; BASFI, Bath Ankylosing Spondylitis Functional Index; BASDAI, Bath Ankylosing Spondylitis Disease Activity Index; ASQLL, Ankylosing Spondylitis Quality of Life questionnaire.

(0-100 mm) score for both nocturnal and total back pain of greater than 30 and acute inflammatory response $(\mathrm{C}$ reactive protein $(\mathrm{CRP})>10 \mathrm{mg} / \mathrm{l})$, and had failed to respond to at least one non-steroidal anti-inflammatory drug (NSAID). All patients had been receiving stable doses of NSAIDs at baseline, with treatment with between one and six NSAIDs (mean three NSAIDs) having failed. None of the patients were receiving corticosteroids, and no patients received any corticosteroids during the study. Disease modifying antirheumatic drugs were discontinued 4 weeks before starting the study. Two patients discontinued methotrexate and two sulfasalazine. Exclusion criteria included psoriasis, inflammatory bowel disease, previous anti-TNF treatment, pregnancy, and known significant concurrent medical disease. Patients were treated with a 3 month course of daily subcutaneous injection of $100 \mathrm{mg}$ anakinra. The efficacy of treatment with anakinra was evaluated by clinical and MRI assessment at the end of the treatment period at week 12 .

\section{Clinical assessment}

Patients were followed up at 2, 8, and 12 weeks after starting anakinra treatment. Patients attended one further follow up after stopping anakinra treatment 2-7 weeks later to assess their response at this point. Clinical outcome measures were collected on each occasion, including VAS scores for patient global assessment (PGA) of disease activity, nocturnal back pain (NBP), total back pain (TBP), Bath AS Functional Index (BASFI), ${ }^{17}$ and Bath AS Disease Activity Index (BASDAI) ${ }^{18}$ The quality of life was assessed based on the AS Quality of Life (ASQoL) questionnaire. ${ }^{19}$ Functional assessments, including the Schober test for lumbar flexion, lumbar side flexion, and chest expansion, were performed on each visit by the same observer (ALT), who also assessed enthesitis using the Maastricht AS Enthesitis Score (MASES). ${ }^{20}$ All patients also had their tender and swollen joint counts recorded at each visit.

Routine laboratory tests, including a full blood count, urea and electrolyte levels, liver function tests, CRP, and erythrocyte sedimentation rate (ESR), were performed at each visit. HLA-B27 type, rheumatoid factor, and antinuclear antibody (ANA) positivity were assessed at baseline, with ANA determination repeated at week 12 .

Patients were also evaluated according to the Assessments in AS (ASAS) Working Group criteria of $20 \%$ improvement at week $12 .{ }^{21}$ This is defined as at least $20 \%$ improvement and

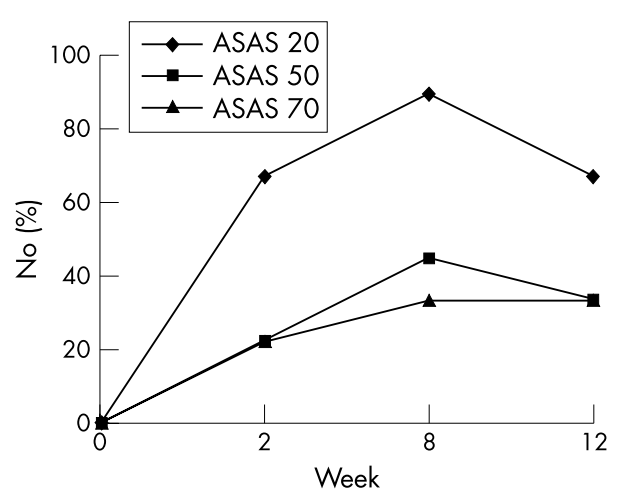

Figure 1 Response to treatment as measured by the ASAS criteria for $20 \%, 50 \%$, and $70 \%$ improvement. By week 2, 67\% $(n=6)$ had achieved ASAS 20\% improvement, which peaked at week 8 with $89 \%(n=8)$. At week $12,67 \%(n=6)$ achieved ASAS 20\% improvement, $33 \%(n=3)$ ASAS $50 \%$ improvement, and $33 \%(n=3)$ ASAS $70 \%$ improvement.

an absolute improvement of at least 10 units on a scale of 0-100 in at least three of the following domains: PGA, pain, function (BASFI), and inflammation (mean of the last two scores in the BASDAI concerning morning stiffness intensity and duration), with absence of deterioration in the remaining domain, where deterioration is defined as a change for the worse of at least $20 \%$ and net worsening of at least 10 units. ASAS $50 \%$ and $70 \%$, defined as $50 \%$ and $70 \%$ improvement as before but not requiring an absolute change of 10 units in the domains, were also assessed in all the patients at week 12 .

\section{Radiography}

All the patients had $x$ ray examinations of the chest, lumbar spine, and sacroiliac joints (SIJs) performed at baseline.

\section{MRI}

Scans were performed at baseline and at week 12 using a 1.5 T Gyroscan ACS NT (Philips, Best, The Netherlands) MRI scanner. $\mathrm{T}_{1}$ weighted turbo spin echo (TSE) and short $\tau$ inversion recovery (STIR) TSE fat suppressed, sagittal sequences of the lumbar spine were obtained. For the SIJs $\mathrm{T}_{1}$ weighted TSE and STIR TSE fat suppressed, coronal oblique sequences were obtained. 

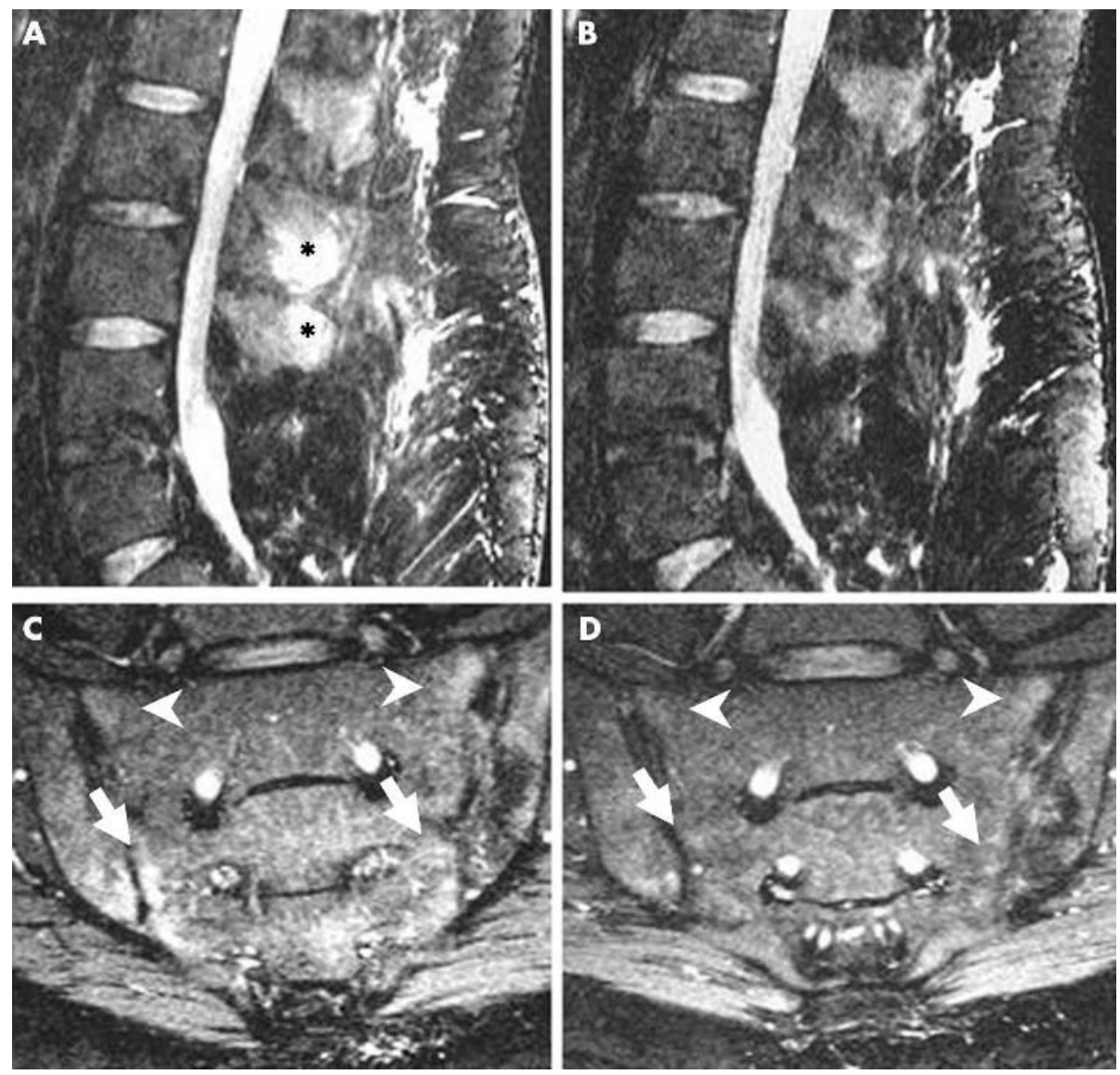

Figure 2 Short $\tau$ inversion recovery (STIR) sagittal magnetic resonance image of the lumbar spine of a patient with ankylosing spondylitis (A) before and (B) after treatment with anakinra, showing resolution of bone oedema in the spinous process at the 2 nd and 3rd lumbar vertebrae (asterisks). (C) STIR coronal oblique sequence of a different patient showing oedema in both SIJs, more extensive on the lower right and left quadrants (arrows). (D) Follow up scan after treatment with anakinra shows almost complete resolution of the oedema at these sites, and improvement of the upper right and left quadrants of the SIJs (arrow heads).

The MRI parameters were as follows: $\mathrm{T}_{1}$ weighted TSE for the spine: repetition time (TR) $666 \mathrm{~ms}$, time to echo (TE) $14 \mathrm{~ms}$, matrix 384/512, field of view (FOV) $375 \mathrm{~mm}$, slice thickness $4.0 \mathrm{~mm}$, slice gap $0.4 \mathrm{~mm}$, number of signals averaged (NSA) 3, and acquisition time $4 \mathrm{~min} 18 \mathrm{~s} ; \mathrm{T}_{1}$ oblique of the SIJ: TR $892 \mathrm{~ms}$, TE $14 \mathrm{~ms}$, matrix 384/512, FOV $320 \mathrm{~mm}$, slice thickness $4.0 \mathrm{~mm}$, slice gap $0.4 \mathrm{~mm}$, NSA 3 , and acquisition time $5 \mathrm{~min} 44 \mathrm{~s}$. The STIR TSE acquisition parameters were TR $2500 \mathrm{~ms}$, TE $10 \mathrm{~ms}$, matrix 382/512, FOV $375 \mathrm{~ms}$ (spine) and $320 \mathrm{~ms}$ (SIJ), slice thickness $4.0 \mathrm{~mm}$, slice gap $0.8 \mathrm{~mm}$, NSA 2, and acquisition time $4 \mathrm{~min} 35 \mathrm{~s}$.

\section{MRI scoring}

A number of areas were systematically analysed for each joint as previously described. ${ }^{2}$ In the SIJs, four quadrants were assessed: right upper, left upper, right lower, and left lower. Each quadrant was subdivided into ilial and sacral aspects. Spinal lesions were classified as present within vertebral bodies, facetal joints, and spinous processes or paraspinal soft tissues. MRI enthesitis was defined on STIR TSE images as bone oedema (high or intermediate marrow signal) and/or soft tissue oedema (high signal in the extracapsular connective tissues) adjacent to the entheses. All features were recorded as present or absent at baseline, and the total number of lesions for each area scanned (SIJ and spine) was counted. The MRI scans before and after treatment with anakinra were scored together, but the assessors were unaware of the order of the scans. Paired scoring was performed by two experienced scorers for every lesion using a semiquantitative scale (resolution, improvement, no improvement, deterioration), with consensus in equivocal cases.

\section{Statistical analysis}

Variables are presented as the median, unless stated otherwise. Wilcoxon's matched pairs signed rank test was used to measure significance of the change from baseline. Values of $\mathrm{p}<0.05$ were considered significant.

\section{RESULTS}

All the patients were male with a mean age of 45 years (range 31-58), mean disease duration of 18.6 years (3-33), all were seronegative for rheumatoid factor, all had radiographic bilateral sacroiliitis and seven of the eight available HLA-B27 results were positive. All the patients had active axial disease (mean VAS $(0-100 \mathrm{~mm}) \quad \mathrm{NBP}=67.8(40-91), \quad \mathrm{TBP}=64.8$ (44-91)). Only one patient had chronic synovitis of both wrists, which persisted throughout the study.

\section{Clinical outcomes}

All nine patients completed the 12 week study. The most significant side effects experienced were injection site reactions in all nine patients and initial transient mild headaches in five patients. The injection site reaction occurred between the start of treatment and 16 days later, and resolved completely by 6 weeks in all patients. No other adverse reactions were seen. Two patients tested weakly 
Table 2 Summary of the scores for magnetic resonance imaging lesions before and after treatment with anakinra*

\begin{tabular}{lllllll}
\hline & & & & & \\
& Baseline & Resolution & Improvement & Unchanged & Deterioration & New lesions \\
\cline { 3 - 7 } & 7 & 0 & $6(86)$ & $1(14)$ & 0 & 0 \\
\hline SIJ & 31 & $7(23)$ & $10(32)$ & $11(35)$ & $3(10)$ & 4 \\
Spine & 38 & $7(18)$ & $16(42)$ & $12(32)$ & $3(8)$ & 4 \\
Totalt & 38 & &
\end{tabular}

*Values are the number (\%) of lesions; ta total of 23 lesions (61\%) either resolved completely or improved.

positive for ANA at $1 / 40$ but were negative after treatment, while one other was weakly positive at $1 / 40$ after treatment.

All outcome measures monitored improved in the patients (table 1). The Schober test (mean baseline $2.06 \mathrm{~cm}, 3$ months $2.44 \mathrm{~cm}, \mathrm{p}=0.176$ ), lumbar side flexion (mean baseline $7.14 \mathrm{~cm}, 3$ months $9.69 \mathrm{~cm}, \mathrm{p}=0.085$ ), chest expansion (mean baseline $2.89 \mathrm{~cm}, 3$ months $3.44 \mathrm{~cm}, \mathrm{p}=0.44$ ), and MASES (mean baseline 1.22, 3 months 0.44, $\mathrm{p}=0.129$ ) all improved after anakinra treatment. Six of the nine patients $(67 \%)$ responded according to the ASAS Working Group criteria of $20 \%$ improvement, and three $(33 \%)$ patients achieved ASAS 50\% and ASAS 70\% (fig 1). Significant improvements in the BASFI $(p=0.021)$, BASDAI $(p=0.028)$, ASQoL $(p=0.011)$, and the VAS score for NBP $(p=0.038)$ were noted. The laboratory assessment of inflammation as determined by CRP and ESR also showed significant improvement (CRP, $\mathrm{p}=0.036$; ESR, $\mathrm{p}=0.008$ ).

All nine patients developed a symptomatic flare between 1 and 2 weeks after they received their last injection of anakinra. All variables measured between 2 and 7 weeks after the last dose of anakinra deteriorated, and this was significant for the ESR $(p=0.012)$, early morning stiffness $(\mathrm{p}=0.012)$, VAS scores for PGA and TBP $(\mathrm{p}=0.011$ and 0.021 , respectively), BASFI $(p=0.028)$, BASDAI $(p=0.019)$, and ASQoL $(\mathrm{p}=0.011)$.

\section{MRI results}

Eight patients had MRI of the lumbar spine and SIJs at baseline and at week 12 with the ninth patient being unable to tolerate repeat scanning (fig 2). Eight patients had a total of 38 MRI detectable entheseal lesions (7 SIJ lesions in two patients, 31 lumbar spine lesions in eight patients). Overall, $23(61 \%)$ entheseal lesions detected by MRI either resolved completely $(n=7)$ or improved $(n=16)$.

Three patients (mean disease duration 21.3 years) had bilaterally ankylosed SIJs. Of the two patients with active osteitis (subchondral oedema), one patient had six lesions and the other had one lesion. All six lesions improved in the first patient who had the shortest disease duration of the nine patients, while the one lesion in the other patient remained unchanged.

In the spine, eight patients had a total of 31 active lesions (table 2). Vertebral body lesions included Romanus lesions $(n=15)$, end plate oedema $(n=3)$, facet joint oedema $(\mathrm{n}=8)$, and spinous process oedema $(\mathrm{n}=5)$. Seventeen lesions $(55 \%)$ improved after treatment. Seven of these lesions $(23 \%)$ resolved completely, while the other 10 lesions (32\%) improved. Eleven lesions remained unchanged, and three of the lesions deteriorated. At week 12 after treatment, four new lesions were noted in two patients, both of whom demonstrated a corresponding deterioration in the VAS for NBP.

\section{DISCUSSION}

This study assessed the clinical efficacy of anakinra in AS and specifically its effect on axial enthesitis and associated osteitis based on MRI evaluation. Improvement was observed in all clinical measures, in particular the laboratory markers of inflammation, back pain, function (BASFI), disease activity (BASDAI), and quality of life (ASQoL). In addition, over half $(61 \%)$ of the MRI detectable lesions either resolved or improved after anakinra treatment. Treatment was well tolerated, although mild injection site reactions occurred initially in all patients. All nine patients became symptomatic soon after treatment was discontinued.

Before the advent of biological treatment such as the TNF $\alpha$ blockers, there was no available proven effective treatment for AS. Our previously published MRI study in resistant SpA shows improvement of axial enthesitis/osteitis determined by MRI after etanercept treatment, and this has been reflected in other randomised controlled trials with infliximab. ${ }^{22}$ The efficacy of anakinra in causing regression of spinal enthesitis/ osteitis is comparable in these two published studies. We have shown that etanercept was associated with an improvement of $86 \%$ of the SpA axial abnormalities on MRI. ${ }^{2}$ In the study by Braun et al, a $60 \%$ improvement in spinal enthesitis/osteitis on STIR sequence after infliximab treatment was reported compared with $21 \%$ deterioration in the placebo group. ${ }^{15}$ Although the $61 \%$ improvement in spinal and SIJ enthesitis/osteitis suggests that anakinra is effective in treating AS, we noted that a few new regions of enthesitis/ osteitis developed, which we did not see in our previous study with etanercept in SpA, suggesting that anakinra may be unable to completely suppress the development of disease in all patients. Nevertheless, even in this small cohort, anakinra had significant clinical efficacy that mirrored a fall in the inflammatory response and was accompanied by a significant improvement in MRI determined axial inflammation, with disease flare when treatment was stopped. After completion of this study and associated disease flares we have restarted anakinra in some patients and have noted good clinical responses and normalisation of the acute phase response in these patients.

In conclusion, this study suggests that anakinra is effective in patients with resistant AS. These findings indicate that ILl has a role in the pathogenesis of spinal enthesitis/osteitis in AS. Anakinra may have a role in patients with AS who cannot tolerate anti-TNF treatment or for whom it has failed, but further randomised controlled trials are needed to formally demonstrate efficacy.

\section{ACKNOWLEDGEMENTS}

We thank sisters Claire Brown and Sally Smith for their help in coordinating this study and Fabio Magrini for help in setting up the study.

This study was supported by an educational grant from Amgen which paid for the supply of anakinra and for the MRI.

\section{Authors' affiliations}

A L Tan, H Marzo-Ortega, A Fraser, P Emery, D McGonagle, Academic Unit of Musculoskeletal Disease, Leeds General Infirmary, Great George Street, Leeds LS1 3EX, UK

P O'Connor, Department of Radiology, Leeds General Infirmary, Great George Street, Leeds LS1 3EX, UK 
A L Tan, D McGonagle, Calderdale Royal Hospital, Salterhebble, Halifax HX3 OPW, UK

\section{REFERENCES}

1 McGonagle D, Marzo-Ortega H, Benjamin M, Emery P. Report on the Second international Enthesitis Workshop. Arthritis Rheum 2003;48:896-905.

2 Marzo-Ortega H, McGonagle D, O'Connor P, Emery P. Efficacy of etanercept in the treatment of the entheseal pathology in resistant spondylarthropathy: a clinical and magnetic resonance imaging study. Arthritis Rheum 2001;44:2112-17.

3 Braun J, Breban M, Maksymowych WP. Therapy for ankylosing spondylitis: new treatment modalities. Best Pract Res Clin Rhematol 2002;16:631-51.

4 Braun J, Sieper J, Breban M, Collantes-Estevez E, Davis J, Inman R, et al. Antitumour necrosis factor alpha therapy for ankylosing spondylitis: international experience. Ann Rheum Dis 2002;61(suppl III):iii51-60.

5 Gorman JD, Sack KE, Davis JC Jr. Treatment of ankylosing spondylitis by inhibition of tumor necrosis factor alpha.[comment]. N Engl J Med 2002;346:1349-56

6 Lipsky PE, van der Heijde DM, St Clair EW, Furst DE, Breedveld FC, Kalden JR, et al. Infliximab and methotrexate in the treatment of rheumatoid arthritis. Anti-Tumor Necrosis Factor Trial in Rheumatoid Arthritis with Concomitant Therapy Study Group[comment]. N Engl J Med 2000;343:1594-602.

7 Bresnihan B, Cunnane G. Interleukin-1 receptor antagonist. Rheum Dis Clin North Am 1998;24:615-28.

8 McGarry F, Neilly J, Anderson N, Sturrock R, Field M. A polymorphism within the interleukin 1 receptor antagonist (IL-1Ra) gene is associated with ankylosing spondylitis. Rheumatology (Oxford) 2001:40:1359-64.

9 Danis VA, March LM, Nelson DS, Brooks PM. Interleukin-1 secretion by peripheral blood monocytes and synovial macrophages from patients with rheumatoid arthritis. J Rheumatol 1987; 14:33-9.

10 Vazquez-Del MM, Garcia-Gonzalez A, Munoz-Valle JF, Garcia-Iglesias T, Martinez-Bonilla G, Bernard-Medina G et al. Interleukin I beta (IL-1 beta), IL10 , tumor necrosis factor-alpha, and cellular proliferation index in periphera blood mononuclear cells in patients with ankylosing spondylitis. J Rheumatol 2002;29:522-6.

11 Nouri AM, Panayi GS, Goodman SM. Cytokines and the chronic inflammation of rheumatic disease. I. The presence of interleukin-1 in synovial fluids. Clin Exp Immunol 1984;55:295-302.
12 Bendele A, McAbee T, Sennello G, Frazier J, Chlipala E, McCabe D. Efficacy of sustained blood levels of interleukin-1 receptor antagonist in animal models of arthritis: comparison of efficacy in animal models with human clinical data. Arthritis Rheum 1999:42:498-506.

13 Maksymowych WP, Jhangri GS, Fitzgerald AA, LeClercq S, Chiu P, Yan A, et al. A six-month randomized, controlled, double-blind, dose-response comparison of intravenous pamidronate $(60 \mathrm{mg}$ versus $10 \mathrm{mg})$ in the treatment of nonsteroidal antiinflammatory drug-refractory ankylosing spondylitis. Arthritis Rheum 2002;46:766-73.

14 Jimi E, Nakamura I, Duong LT, Ikebe T, Takahashi N, Rodan GA, et al. Interleukin 1 induces multinucleation and bone-resorbing activity of osteoclasts in the absence of osteoblasts/stromal cells. Exp Cell Res 1999;247:84-93.

15 Braun J, Baraliakos X, Golder W, Brandt J, Rudwaleit M, Listing J, et al. Magnetic resonance imaging examinations of the spine in patients with ankylosing spondylitis, before and after successful therapy with infliximab: evaluation of a new scoring system. Arthritis Rheum 2003;48:1126-36.

16 van der Linden S, Valkenburg HA, Cats A. Evaluation of diagnostic criteria for ankylosing spondylitis. A proposal for modification of the New York criteria. Arthritis Rheum 1984;27:361-8.

17 Calin A, Garrett S, Whitelock H, Kennedy LG, O'Hea J, Mallorie P, et al. A new approach to defining functional ability in ankylosing spondylitis: the development of the Bath Ankylosing Spondylitis Functional Index. J Rheumatol 1994;21:2281-5.

18 Garrett S, Jenkinson T, Kennedy LG, Whitelock H, Gaisford P, Calin A. A new approach to defining disease status in ankylosing spondylitis: the Bath Ankylosing Spondylitis Disease Activity Index. I Rheumatol 1994;21:2286-91.

19 Helliwell PS, Doward L, Whalley D, Tennant A, McKenna S, Reynolds S, et al. Psychometric and scaling properties of a new quality of life instrument specific to ankylosing spondylitis. Arthritis Rheum 1999;42(9):S72.

20 Heuft-Dorenbosch L, Spoorenberg A, van Tubergen A, Landewe R, van der Tempel $H$, Mielants $H$, et al. Assessment of enthesitis in ankylosing spondylitis. Ann Rheum Dis 2003;62:127-32.

21 Anderson JJ, Baron G, van der Heijde D, Felson DT, Dougados M. Ankylosing spondylitis assessment group preliminary definition of short-term improvement in ankylosing spondylitis[comment]. Arthritis Rheum 2001;44:1876-86.

22 Braun J, Brandt J, Listing J, Zink A, Alten R, Golder W, et al. Treatment of active ankylosing spondylitis with infliximab: a randomised controlled multicentre trial. Lancet 2002;359:1187-93. 